This cycle is being maintained throughout the series of experiments, which will cover a period of about four months. In addition, the point of release of each balloon is adjusted to ensure that the seedingagent is always released over the same point, this point being in the centre of the Kongwa area of cultivation. As this area is covered with a two-mile grid of rain-gauges, a detailed analysis of rainfall over the area surrounding the point of seeding will be possible.

The aim is thus to carry out a series of experiments which are strictly controlled both in time and space and which are maintained over a fairly long period. It is my belief that positive deductions from any experiments on artificial stimulation of rain are most likely to emerge if the experiments are conducted on such a basis.

${ }^{1}$ Davies, D. A., Nature, 167, 614 (1951).

'Ludlam F. H., Quart. J. Roy. Meteor. Soc., 77, 402 (1951).

\section{MICHAELSEN INSTITUTE OF THE UNIVERSITY OF COPENHAGEN} NEW Institute at the University of Copenhagen,
to be known as the Michaelsen Institute, has
been sponsored jointly by the Michaelsen Foundation,
the Carlsberg Foundation, the Rockefeller Foundation
and the Danish State, and the building was formally
opened on April 16. It houses the Institute of
Neurophysiology (director, Prof. Fritz Buchthal) and
the Isotope Section of the Zoophysiological Labor-
atory (director, Prof. H. H. Ussing).
Work in the Institute of Neurophysiology is a
continuation of the research carried out since 1933
in the Laboratory for the Theory of Gymnastics,
mainly concerned with problems of the physiology
of striated muscle and the motor system. In the
main, the programme is concerned with the properties
of single muscle fibres from various aspects : static
and dynamic properties are being investigated in the
longitudinal and transverse direction of the muscle
fibre, determining longitudinal and torsional elas-
ticity, both at rest and during contraction, the aim
being to gain information on the minute structural
properties of the fibre and their changes during
activity. Attempts are being made to correlate these
findings with measurements of birefringence and with
direct studies of minute structure as revealed by the
electron microscope and X-ray diffraction.

The electrical response of the single fibre, both in situ and isolated, is being studied, special stress being put on the influence of the measuring electrode and the surrounding inactive tissue on the parameters of the action potential. After a study of the physical and physiological factors influencing the muscle action potential during voluntary effort, the findings are being applied to action potential analysis in nouro-muscular disorders. A three-channel cathoderay oscillograph has been developed for the amplification and recording of action potentials, and this permits the use of micro-electrodes with high impedance (input impedance of the amplifiers $>40 \times 10^{8} \mathrm{ohms}$ at $50 \mathrm{c} . / \mathrm{s}$.). A study is in progress dealing with the functional organization of motor unit activity in voluntary contraction.

The mechanical properties of striated muscle are to be correlated with both chemical and electrical reactions. The chemical assay of elements of the nucleotide system is being performed during the development of twitch tension in slowly contracting muscles, which makes it possible to arrest contraction by freezing to $-150^{\circ} \mathrm{C}$. in the initial phase of a twitch. In connexion with these studies, experiments are being continued on model chemical systems, studying the factors governing the phosphate uptake of myosin threads and solutions when nucleotide is applied to them.

Other problems being pursued relate to neuromuscular transmission and the influence of different local anæsthetics on propagation velocity in nerve; with the effect of cholinergic substances on cold and pain receptors in the skin; and with the cerebral representation of colour vision.

The activities of the Institute are concerned only with research, and the staff has no teaching obligations. It does, however, act in a consultative capacity, especially to the Neuromedical and Neurosurgical Divisions of the University Hospital, and the Institute is available for postgraduate training.

The equipment consists of the usual amplifying and recording devices for electrophysiological work, micro-manipulators, and tension and length recorders for work on isolated fibres. This equipment has in part been developed by the physiological and the engineering staff, and has been constructed in the workshop of the Institute.

Work in the Isotope Laboratory is concerned with the study of the active transport of inorganic ions across isolated surviving animal membranes. An experimental device has been developed by which it is possible to determine the part played by any particular active transport process in producing electric currents in a short-circuited living membrane. Thus, it has been demonstrated that the electric current generated by the isolated frog skin-in contact with Ringer solution on both sides-arises solely from active transport inward of sodium ions. It is intended to study the kinetics and dependency upon metabolic poisons of this and other active transport systems. The detailed analysis of the ionic movements is performed by means of isotopes. The Laboratory has available a number of conventional Geiger-Müller counters and also possesses arrangements for the automatic counting of radioactive samples. Moreover, there are facilities for determining heavy water according to the gradient-tube method; at present, this equipment is being used for determining the total water phase in dehydrated infants, but its main use is in connexion with the study of the permeability of living membranes to water. A separate project is concerned with the further development of radioautographic methods. The major aim of this work is to obtain quantitative autography of hard beta-ray emitters. Besides doing research of their own, the members of the staff act as advisers on isotope work to scientific workers from other laboratories.

Three floors of the Michaelsen Institute are occupied by the Institute of Neurophysiology, and one floor by the Isotope Section of the Zoophysiological Laboratory. The former has available eleven laboratories and a library, one small workshop for use of the staff and a machine shop for the construction of equipment, one chemical laboratory, including a cold room, a constant-temperature room, an operating room, a room for post-operative animals, and a dark room on each floor. The Isotope Laboratory has at its disposal seven laboratories and a small workshop. 
The rooms are of a standard size, $5.4 \mathrm{~m} . \times 4.4 \mathrm{~m}$. Installations (gas, water, compressed air and a reserve pipe) are led around the room over and under a small shelf $(27 \mathrm{~cm}$.) fixed to the wall at table height, and water outlets are built in this shelf. Electrical installations are separate, with a main switch for each room. The wiring consists of lead-shielded cables which are led around the room with multiple outlets at every $1 \frac{1}{2} \mathrm{~m}$. for $220 \mathrm{~V}$. D.C., 110 and $220 \mathrm{~V}$. A.C., battery voltage and earth. In addition, one of these outlet boxes, with flexible connexions, is placed in the middle of the room. The potential difference between the conducting surfaces in a laboratory (screen of electrical installations, gas and water pipes, etc.) is less than $10 \mathrm{mV}$. Ice boxes in five of the laboratories are supplied by a central refrigerating unit. They contain a refrigerating mixture which can be piped to any desired location.

The furniture consists of interchangeable units, $1.08 \mathrm{~m} . \times 0.5 \mathrm{~m}$., tables, and drawer and shelf cupboards. By standardizing the room-size, installation and furniture, it has been possible to keep the building expenses to a reasonable figure (£13/cu. m.).

\section{UNITED STATES NATIONAL ACADEMY OF SCIENCES}

$\mathrm{A}$

$\mathrm{T}$ the annual general meeting of the United States National Academy of Sciences, held in Washington, D.C., during April 28-30, the following officers, new members and foreign associates were elected.

Treasurer: W. J. Robbins, director of the New York Botanical Garden, for a further four-year term.

New Members of Council : R. F. Loeb, professor of medicine, College of Physicians and Surgeons, New York ; and W. M. Stanley, chairman of the Department of Biochemistry, University of California, Berkeley.

New Members : F. Albright, associate professor of medicine, Harvard Medical School; R. McL. Badger, professor of chemistry, California Institute of T'echnology; H. R. Byers, chairman of the Department of Meteorology, University of Chicago ; C. Chevalley, professor of mathematics, Columbia University ; G. M. Clemence, head astronomer, United States Naval Observatory, Washington, D.C. ; L. R. Cleveland, professor of zoology, Harvard University ; J. S. Fruton, professor of biochemistry, Yale University School of Medicine; C. H. Greenewalt, president of E. I. du Pont de Nemours and Co., Inc., Wilmington, Del.; D. T. Griggs, professor of geophysics, Institute of Geophysics, University of California, Los Angeles; S. B. Hendricks, chief chemist, Bureau of Plant Industry, Soils and Agricultural Engineering, U.S.D.A., Beltsville, Md.; H. H. Hess, head of the Department of Geology, Princeton University; C. L. Hubbs, professor of biology, Scripps Institute of Oceanography, La.Jolla, Cal. ; W. S. Johnson, professor of organic chemistry, University of Wisconsin; B. P. Kaufmann, Department of Genetics, Carnegie Institution, Cold Spring Harbor, N.Y.; C. K. M. Kluckhohn, professor of anthropology, Harvard University; D. B. Lindsley, professor of psychology, University of California, Los Angeles; P. D. McMaster, member of the Rockefeller Institute for Medical Research, New York ; C. G. Niemann, professor of organic chemistry, California Institute of Technology ; C. L.
Pekeris, member of the Institute for Advanced Study, Princeton; N. F. Ramsey, jun., professor of physics, Harvard University ; E. Segre, professor of physics, University of California, Berkeley ; R. Serber, professor of physics, Columbia University; F. H. Spedding, head of the Department of Physical Chemistry, Iowa State College; L. Spitzer, jun., director of Princeton University Observatory; G. L. Stebbins, jun., professor of genetics, University of California, Berkeley; E. L. Tatum, professor of biology, Stanford University; V. F. Weisskopf, professor of physics, Massachusetts Institute of Technology; J. A. Wheeler, professor of physics, Princeton University ; J. W. Williams, professor of chemistry, University of Wisconsin; and D. W. Woolley, member of the Rockefeller Institute for Medical Research, New York.

Foreign Associates: N. Bjerrum, professor of chemistry, Royal Veterinary and Agricultural College, Copenhagen; T. Reichstein, director of the Organic Laboratories, University of Basle; and $H$. U. Sverdrup, director of the Norsk Polarinstitutt, Oslo.

The following four gold medals have been awarded by the Academy : Alexander Agassiz Medal, to Dr. Harry A. Marmer, United States Coast and Geodetic Survey; Henry Draper Medal, to the late Dr. Bernard Lyot, Meudon Observatory, Paris ; Daniel Giraud Elliot Medal, to Dr. Henry B. Bigelow, Harvard University; and James Craig Watson Medal, to Dr. Herbert R. Morgan, Yale University.

The Agassiz Gold Medal, established by Sir John Murray in 1911, is awarded "for original contribution in the science of oceanography to scientific men in any part of the world". Dr. Marmer, in addition to his leadershlip in the programme of tidal surveys along the coasts of the United States and its dependencies, initiated the co-operative tidal programme on the west coast of South America in 1941, and the tidal survey of the western Pacific Islands in 1947. These projects have made available to oceanographers accurate, long-period records for large areas where previously very few observational data were available. He has introduced methods, analyses and criteria which permit the separation of the effects of local crustal deformation from those of eustatic changes in sea-level.

The Draper Medal, which the Academy bestows from time to time in recognition of outstanding contributions in the field of astrophysics, has been awarded to Dr. Lyot for his work in solar physics and in particular for his development of the coronograph, whereby the inner corona of the sun may be observed continuously; previously it had only been possible to observe the solar corona at times of a total solar eclipse. Dr. Lyot, who died recently in Cairo while directing the French solar eclipse expedition at Khartoum, was elected a foreign associate of the Academy in 1949.

Dr. Bigelow is the senior author of "Fishes of the Western North Atlantic", Part 1, published in 1948 as Memoir No. 1 of the Sears Foundation for Marine Research, and it is for this that he receives the Elliot Medal, which is for the year 1948, an award which is made annually to the author of the work in zoology or palæontology considered by the Academy to be the most meritorious of the year. The volume covers in three separate parts the lancelets, the cyclostomes and the sharks, with Dr. Bigelow as senior author for each part and associated in each with another author. Dr. Bigelow has been a moving spirit in work on the fish fauna of the 